\title{
Insulin Stimulates Volume Absorption in the Rabbit Proximal Convoluted Tubule
}

\author{
Michel Baum \\ Department of Pediatrics, University of Texas Health Science Center at Dallas, Dallas, Texas 75235
}

\begin{abstract}
The present in vitro microperfusion study examined whether insulin affects volume absorption $\left(J_{y}\right)$ in the proximal convoluted tubule (PCT). PCT were perfused with an ultrafiltrate-like solution and were bathed in a serum-like albumin solution. Addition of a physiologic concentration of $10^{-10} \mathrm{M}$ insulin to the bathing solution resulted in a stimulation of $J_{v}$ and a more negative transepithelial potential difference (PD). There was a progressive stimulation of the lumen negative PD and $J$, with higher insulin concentrations. Maximal stimulation occurred at $10^{-8} \mathrm{M}$ bath insulin. The insulin-induced stimulation of volume reabsorption was also observed when glucose and amino acids were removed from the luminal perfusate. Direct examination of the effect of insulin on glucose, chloride, and bicarbonate absorption demonstrated that the transport of all these solutes was stimulated by insulin. Addition of insulin to the luminal perfusate had no affect on $J_{v}$. These data show that insulin has a direct effect to stimulate $J_{v}$ in the proximal tubule.
\end{abstract}

\section{Introduction}

Several studies have provided evidence that insulin decreases urinary sodium excretion (1-5). Withdrawal of insulin in humans with diabetes mellitus results in a diuresis and natriuresis that may not be due solely to the observed glucosuria and ketonuria. Readministration of insulin causes sodium retention, suggesting a possible role for insulin in sodium reabsorption by the kidney $(1,3)$. Administration of insulin to isolated dog kidneys where the glomerular filtration rate and filtered load of sodium remained constant results in a decrease in sodium, potassium, and water excretion (2). Further evidence for a direct effect of insulin on sodium excretion was demonstrated in human studies where insulin was administered and blood glucose was maintained at a constant level. Although glomerular filtration rate and renal blood flow remained unchanged, urinary sodium, potassium, and phosphate excretion decreased with insulin administration (4).

The nephron segments involved in the stimulation of sodium reabsorption are unknown. Although there are insulin receptors on the proximal tubule (6-11), previous studies have provided evidence against insulin-stimulating volume absorption $\left(J_{v}\right)^{1}$ in

Address correspondence and reprint requests to Dr. Baum, Department of Pediatrics, University of Texas Health Science Center at Dallas, 5323 Harry Hines Boulevard, Dallas, TX 75235. 1986.

Received for publication 16 June 1986 and in revised form 8 September

1. Abbreviations used in this paper: $J_{v}$, volume absorption; $P D$, potential difference; PCT, proximal convoluted tubule.

J. Clin. Invest.

(c) The American Society for Clinical Investigation, Inc. 0021-9738/87/04/1104/06 \$1.00

Volume 79, April 1987, 1104-1109 the proximal tubule $(4,5,12)$. The purpose of the present in vitro microperfusion study was to examine directly whether insulin affects transport in the proximal tubule. The data show that both physiologic and pharmacologic concentrations of insulin stimulate volume reabsorption in the proximal tubule. These data provide the first direct evidence that the decrease in sodium excretion observed with hyperinsulinemia can, in part, be explained by a stimulation in proximal tubule volume reabsorption.

\section{Methods}

Isolated segments of randomly dissected midcortical and juxtamedullary rabbit proximal convoluted tubules (PCT) were perfused as previously described (13-16). Briefly, kidneys from female New Zealand white rabbits were cut in coronal slices. Individual tubules were dissected in cooled $\left(4^{\circ} \mathrm{C}\right)$ ultrafiltrate-like solution containing $115 \mathrm{mM} \mathrm{NaCl}, 25 \mathrm{mM}$ $\mathrm{NaHCO}_{3}, 2.3 \mathrm{mM} \mathrm{Na}_{2} \mathrm{HPO}_{4}, 10 \mathrm{mM} \mathrm{Na}$ acetate, $1.8 \mathrm{mM} \mathrm{CaCl}_{2}, 1 \mathrm{mM}$ $\mathrm{MgSO}_{4}, 5 \mathrm{mM} \mathrm{KCl}, 8.3 \mathrm{mM}$ glucose, and $5 \mathrm{mM}$ alanine.

Tubules were perfused with the above ultrafiltrate-like solution and bathed in a similar solution containing $6 \mathrm{~g} / \mathrm{dl}$ albumin. All solutions were bubbled with $95 \% \mathrm{O}_{2}$ and $5 \% \mathrm{CO}_{2}$ and had a pH of 7.40. The osmolality of the bath and perfusate were adjusted to 295 by the addition of either $\mathrm{H}_{2} \mathrm{O}$ or $\mathrm{NaCl}$. To maintain the $\mathrm{pH}$ and bath osmolality constant, bath fluid was continuously changed at a rate of at least $0.5 \mathrm{ml} / \mathrm{min}$. All tubules were perfused at $\sim 10 \mathrm{nl} / \mathrm{min}$ at $38^{\circ}-39^{\circ} \mathrm{C}$ in a $1.2 \mathrm{ml}$ temperature-controlled bath. The first period began after an equilibration time of 30-60 min. Subsequent periods were separated by an equilibration time of at least $30 \mathrm{~min}$.

Net $J_{\mathrm{v}}$ (in nanoliters per millimeter per minute) was measured as the difference between the perfusion $\left(V_{0}\right)$ and collection $\left(V_{L}\right)$ rates (nanoliters per minute) normalized per millimeter of tubular length $(L)$. Exhaustively dialyzed [methoxy- ${ }^{3} \mathrm{H}$ ] inulin was added to the perfusate at a concentration of $50 \mu \mathrm{Ci} / \mathrm{ml}$ so that the perfusion rate could be calculated. The collection rate was measured with a 60-nl constant-volume pipette. The length, in millimeters, was measured with an eyepiece micrometer.

Net total $\mathrm{CO}_{2}$ flux ( $J_{\mathrm{TCO}_{2}}$, picomoles per millimeter per minute) and net chloride flux ( $J_{\mathrm{C}}$, picoequivalents per millimeter per minute) were calculated according to the equation: $J_{\mathrm{C} \text { or }} J_{\mathrm{TCO}_{2}}=\left(V_{0} C_{0}-V_{\mathrm{L}} C_{\mathrm{L}}\right) / \mathrm{L}$, where $C_{0}$ and $C_{\mathrm{L}}$ represent the concentration of chloride or $\mathrm{TCO}_{2}$ in the perfused and collected fluid, respectively. $\mathrm{TCO}_{2}$ measurements were performed using microcalorimetry (Picapnotherm, model GVI; World Precision Instruments, Inc. New Haven, CT) (17). Chloride measurements were performed using the electrometric titration technique of Ramsay (microtitrator model FT-2230; World Precision Instruments, Inc.) (18).

To examine whether insulin affected glucose transport, $50 \mu \mathrm{Ci} / \mathrm{ml}$ of $\left[{ }^{14} \mathrm{C}\right]$ glucose (ICN Pharmaceuticals, Inc., Irvine, CA) was added to the perfusate. Glucose transport was calculated according to the equation: $J_{\mathrm{Glu}}=\left[\left(V_{0} C_{0}{ }^{*}-V_{\mathrm{L}} C_{\mathrm{L}}^{*}\right) / L\right]\left(G_{0} / C_{0}^{*}\right)$, where $\left[G_{0}\right]$ is the glucose concentration in the perfusate and $C_{0}^{*}$ and $C_{\mathrm{L}}^{*}$ are the concentration of $\left[{ }^{14} \mathrm{C}\right]$ glucose in cpm per nanoliter in the perfused and collected fluid, respectively. In experiments where chloride, bicarbonate, and $\left[{ }^{14} \mathrm{C}\right]$ glucose were measured, alternate samples were taken for the measurement of $J_{v}$ and $\left[{ }^{14} \mathrm{C}\right]$ glucose, bicarbonate, and chloride.

The transepithelial potential difference (PD, in millivolts) was measured by using the perfusion pipette as the bridge into the tubular lumen. The perfusion and bath solutions were connected to the recording and reference calomel half-cells, respectively, via a bridge containing perfusion 
Table I. Effect of Insulin on the PCT

\begin{tabular}{|c|c|c|c|c|c|c|c|c|c|c|}
\hline \multirow{2}{*}{$\begin{array}{l}\text { Experimental } \\
\text { protocol }\end{array}$} & \multirow[b]{2}{*}{$n$} & \multicolumn{3}{|l|}{$V_{0}$} & \multicolumn{3}{|l|}{$J_{v}$} & \multicolumn{3}{|l|}{ PD } \\
\hline & & Control & Experimental & Recovery & Control & Experimental & Recovery & Control & Experimental & Recovery \\
\hline & & $n l / m i n$ & $\mathrm{nl} / \mathrm{min}$ & $n l / m i n$ & $\mathrm{nl} / \mathrm{mm} \cdot \min$ & $\mathrm{nl} / \mathrm{mm} \cdot \mathrm{min}$ & $\mathrm{nl} / \mathrm{mm} \cdot \min$ & $m V$ & $m V$ & $m V$ \\
\hline $\begin{array}{l}\text { Time control } \\
10^{-11} \mathrm{M} \text { Bath }\end{array}$ & 4 & $10.34 \pm 0.49$ & $10.00 \pm 0.45$ & & $0.86 \pm 0.06$ & $0.87 \pm 0.08$ & & $-4.3 \pm 0.4$ & $-4.5 \pm 0.5$ & - \\
\hline $\begin{array}{c}\text { insulin } \\
10^{-10} \mathrm{M} \text { Bath }\end{array}$ & 5 & $10.23 \pm 0.13$ & $10.45 \pm 0.18$ & $10.46 \pm 0.07$ & $0.79 \pm 0.06$ & $0.80 \pm 0.04$ & $0.79 \pm 0.04$ & $-3.5 \pm 0.6$ & $-3.6 \pm 0.6$ & $-4.0 \pm 0.6$ \\
\hline $\begin{array}{c}\text { insulin } \\
10^{-9} \mathrm{M} \text { Bath }\end{array}$ & 6 & $9.84 \pm 0.27$ & $9.97 \pm 0.17$ & $10.27 \pm 0.15$ & $0.69 \pm 0.06$ & $0.78 \pm 0.08^{*}$ & $0.71 \pm 0.08^{\S}$ & $-3.3 \pm 0.6$ & $-4.0 \pm 0.7^{\dagger}$ & $-4.2 \pm 0.8$ \\
\hline $\begin{array}{l}\text { insulin } \\
10^{-8} \mathrm{M} \text { Bath }\end{array}$ & 6 & $10.05 \pm 0.36$ & $10.71 \pm 0.48^{*}$ & $10.76 \pm 0.24$ & $0.73 \pm 0.09$ & $0.87 \pm 0.09^{*}$ & $0.83 \pm 0.09^{8}$ & $-4.9 \pm 0.5$ & $-5.9 \pm 0.5^{\dagger}$ & $-5.8 \pm 0.5$ \\
\hline $\begin{array}{l}\text { insulin } \\
10^{-7} \mathrm{M} \text { Bath }\end{array}$ & 4 & $12.66 \pm 0.45$ & $13.28 \pm 0.73$ & $13.33 \pm 0.37$ & $0.65 \pm 0.10$ & $0.88 \pm 0.13^{*}$ & $0.92 \pm 0.12$ & $-4.2 \pm 0.4$ & $-5.4 \pm 0.2^{*}$ & $-5.5 \pm 0.2$ \\
\hline $\begin{array}{l}\text { insulin } \\
10^{-6} \mathrm{M} \text { Bath }\end{array}$ & 3 & $9.93 \pm 0.43$ & $10.94 \pm 0.08$ & $11.16 \pm 0.36$ & $0.76 \pm 0.11$ & $0.97 \pm 0.10^{\dagger}$ & $0.93 \pm 0.12$ & $-4.3 \pm 0.6$ & $-5.8 \pm 0.9^{*}$ & $-5.7 \pm 1.0$ \\
\hline insulin & 5 & $9.99 \pm 0.48$ & $10.43 \pm 0.36$ & $10.48 \pm 0.42$ & $0.77 \pm 0.13$ & $0.95 \pm 0.13^{*}$ & $0.99 \pm 0.12$ & $-4.4 \pm 0.3$ & $-5.7 \pm 0.4^{\dagger}$ & $-5.8 \pm 0.5$ \\
\hline
\end{tabular}

Values are means \pm SEM. ${ }^{*}$ Mean paired difference from control significant at the 0.05 level. ${ }^{\dagger}$ Mean paired difference from control significant at the 0.01 level. ${ }^{8} \mathrm{Mean}$ paired difference from experimental significant at the 0.05 level.

or an ultrafiltrate of the bathing solution in series with a $3.6 \mathrm{M} \mathrm{KCl} / 0.9$ $\mathrm{M} \mathrm{KNO}_{3}$ agarose bridge. This arrangement avoided direct contact of $\mathrm{KCl} / \mathrm{KNO}_{3}$ agarose bridges with the solution that bathed the tubule. In addition, this arrangement eliminates the Donnan potential when the bath contains protein (14). The recording and reference calomel halfcells were connected to the high and low impedance side, respectively, of an electrometer (model 602; Keithley Instruments, Inc., Cleveland, $\mathrm{OH}$ ).

To examine whether insulin has an effect on $J_{\mathrm{v}}$ and transepithelial PD in the PCT, tubules were perfused with an ultrafiltrate-like solution and bathed in a serum-like albumin solution. During the experimental period either $0,10^{-11}, 10^{-10}, 10^{-9}, 10^{-8}, 10^{-7}$, or $10^{-6} \mathrm{M}$ insulin was added to the bathing solution. Insulin was either added directly to the bathing solution, or from a $10^{-6} \mathrm{M}$ stock solution mixed with isotonic $\mathrm{NaCl}$. Insulin was removed during the recovery period. Glucose and amino acids were removed from the perfusate and replaced with $\mathrm{NaCl}$ to examine if the effect of insulin was due solely to a stimulation of transport by these solutes. During the experimental period $10^{-8} \mathrm{M}$ insulin was added to the bathing solution. To examine directly the effect of insulin on glucose, chloride, and bicarbonate absorption, transport of these solutes was measured directly in the control period and after the addition of $10^{-8} \mathrm{M}$ bath insulin. In experiments designed to examine if insulin stimulates active $\mathrm{NaCl}$ transport, tubules were perfused with a high chloride solution that contained $138.5 \mathrm{mM} \mathrm{NaCl}, 5 \mathrm{mM} \mathrm{Na} \mathrm{HCO}$, $4 \mathrm{mM} \mathrm{Na}_{2} \mathrm{HPO}_{4}, 1 \mathrm{mM} \mathrm{CaCl}_{2}, 1 \mathrm{mM} \mathrm{MgCl}_{2}, 5 \mathrm{mM} \mathrm{KCl}$, and $5 \mathrm{mM}$ urea. The tubules were bathed in a similar solution that contained $6 \mathrm{~g} /$ $\mathrm{dl}$ albumin. In the bathing solution, $5 \mathrm{mM}$ urea and $1 \mathrm{mM} \mathrm{CaCl}_{2}$ were replaced by $5 \mathrm{mM}$ glucose and alanine and $2 \mathrm{mM} \mathrm{CaCl}_{2}$, respectively. In this setting the perfusate and bathing solutions are in approximate Donnan equilibrium and anion gradients responsible for passive $\mathrm{NaCl}$ transport are eliminated. High chloride solutions were bubbled with $99 \%$ $\mathrm{O}_{2}$ and $1 \% \mathrm{CO}_{2}$ and had a pH of 7.40. During the experimental period, $10^{-8} \mathrm{M}$ insulin was added to the bathing solution. In the final series of experiments designed to examine if insulin has an effect if added on the apical membrane, $10^{-8} \mathrm{M}$ insulin was added to the luminal perfusate during the experimental period.

There were at least four measurements of each parameter in a given period for each tubule. The mean values for individual periods in a given tubule were used to calculate the mean value for that period. ${ }^{2}$ Data are

2. Samples were counted for an average of $27 \mathrm{~min}$ with an average of $2,380 \pm 117 \mathrm{cpm} / \mathrm{sample}$. The average mean counts per sample was 64,000 expressed as a mean \pm SEM. The $t$ test for paired data was used to determine statistical significance.

\section{Results}

The first group of 33 experiments examined whether bath insulin has an effect on $J_{\mathrm{v}}$ and PD in the PCT. The mean tubular length was $1.5 \pm 0.1 \mathrm{~mm}$. Table I shows the results of these experiments. A time control confirmed previous studies that have shown that $J_{v}$ and PD are stable in the PCT under these conditions (15). $10^{-11} \mathrm{M}$ bath insulin had no effect on $J_{\mathrm{v}}$ and PD. A physiologic concentration of $10^{-10} \mathrm{M}$ insulin resulted in a significant stimulation of $J_{\mathrm{v}}$ and PD (Fig. 1). $10^{-9} \mathrm{M}$ insulin resulted in a greater stimulation in both $J_{\mathrm{v}}$ and PD. Maximal stimulation of $J_{\mathrm{v}}$ and PD occurred at $10^{-8} \mathrm{M}$ insulin with no further increase at higher concentrations. Half-maximal stimulation of $J_{\mathrm{v}}$ and PD occurred at a physiologic concentration of $10^{-10} \mathrm{M}$. The stimulation of $J_{\mathrm{v}}$ by $10^{-10}$ and $10^{-9} \mathrm{M}$ bath insulin was reversed upon removal of bath insulin. The stimulation in $J_{v}$ persisted in the recovery period when higher concentrations were examined. The stimulation of the PD persisted at all concentrations. Figs. 2 and 3 depict the percent stimulation of various concentrations of insulin on $J_{\mathrm{v}}$ and PD, respectively. Because most concentrations were not reversible, the difference depicted reflects that between the control and experimental period.

At $10^{-9} \mathrm{M}$ insulin there was a small, but statistically significant increase in perfusion rate. To examine if this increase in perfusion rate affected the data, I perfused five tubules at $9.97 \pm 0.25 \mathrm{nl} / \mathrm{min}$ in the control period and increased the perfusion rate to $11.39 \pm 0.35(P<0.01)$ in the experimental period. $J_{v}$ was $0.86 \pm 0.11$ in the control period and $0.84 \pm 0.12$ at the

making the counting error, a square-root function of the total counts, $\sim 0.4 \%$ per sample. In tubules perfused without organic solutes the rate of volume absorption and the differences between the control and experimental period were smaller. In these experiments there were five collections per period and an average of $129,000 \mathrm{cpm}$ per sample. The counting error per sample was $\sim 0.3 \%$. 

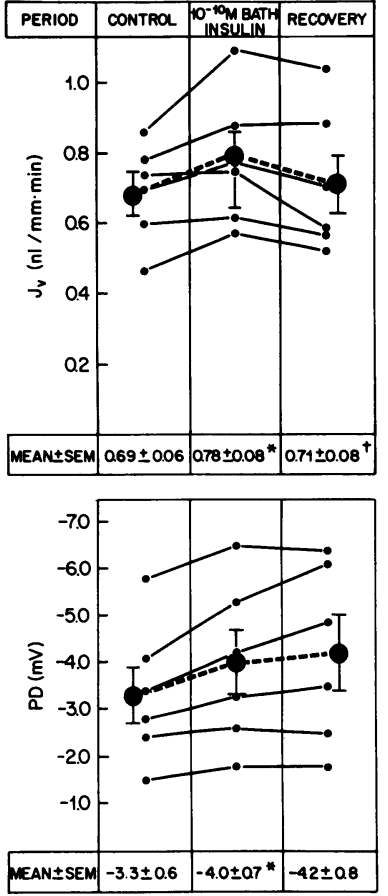

Figure 1. Effect of $10^{-10} \mathrm{M}$ insulin on $J_{\mathrm{v}}$ and PD in the PCT. *Mean paired difference from control at 0.05 level. $†$ Mean paired difference from experimental at 0.05 level.

faster rate. PD was $-3.8 \pm 0.4$ at the slower rate and $-3.9 \pm 0.4$ at the faster rate. Thus, small changes in perfusion rate did not affect the data.

In the next series of experiments, glucose and amino acids were replaced by $\mathrm{NaCl}$ to examine if the stimulation of $J_{\mathrm{v}}$ was due solely to a stimulation of glucose and amino acid transport. The mean tubular length was $1.6 \pm 0.1 \mathrm{~mm}$ and the perfusion rate was $9.51 \pm 0.23,9.92 \pm 0.17$, and $9.89 \pm 0.13 \mathrm{nl} / \mathrm{min}$ in the control, experimental, and recovery period, respectively. Fig. 4 shows the results of these experiments. There was a small lumen positive PD probably secondary to the anion concentration gradient resulting from the additional $\mathrm{NaCl}$ in the perfusate which was not affected by insulin (16). Addition of insulin produced a significant stimulation in $J_{\mathrm{v}}$ consistent with insulin stimulating the transport of other solutes besides glucose and amino acids.

The next series of experiments was designed to examine the effect of insulin on glucose, bicarbonate, and chloride transport in the PCT. The mean tubular length was $2.0 \pm 0.1 \mathrm{~mm}$ and the perfusion rate was $8.60 \pm 0.09,9.46 \pm 0.14$, and $9.42 \pm 0.11 \mathrm{nl} /$ min in the control, experimental, and recovery periods, respectively. The difference in the perfusion rate between the control and experimental period, although small, was statistically significant. Table II and in Fig. 5 show the results. In these six

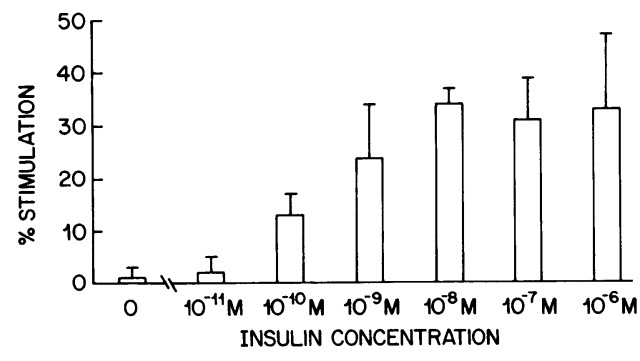

Figure 2. Percent stimulation of $J_{v}$ by bath insulin.

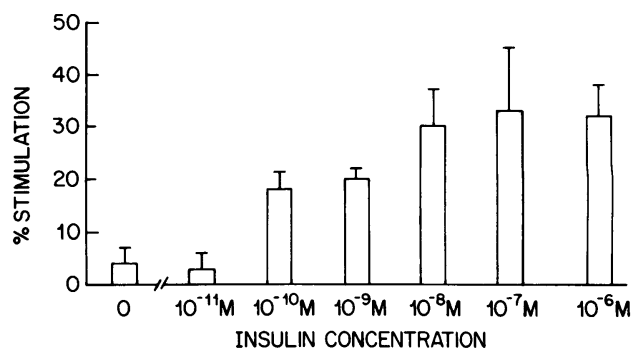

Figure 3. Percent stimulation of PD by bath insulin.

tubules, the perfusate bicarbonate concentration was $24.7 \pm 0.1$ milliequivalents per liter and decreased to $17.7 \pm 0.8,16.3 \pm 1.3$, and $16.9 \pm 1.2 \mathrm{meq} / \mathrm{liter}$ in the control, experimental and recovery periods, respectively. The perfusate chloride concentration was $115.8 \pm 0.8$ and increased to $130.1 \pm 2.1,126.6 \pm 2.2$, and $128.6 \pm 1.6 \mathrm{meq} /$ liter in the control, experimental, and recovery periods, respectively. These data show directly that insulin stimulates bicarbonate, chloride, and glucose absorption in the PCT.

The next series of experiments was designed to examine if insulin stimulates active $\mathrm{NaCl}$ transport. In this series tubules were perfused with a high chloride solution simulating late proximal tubular fluid and bathed in a similar solution containing albumin. The mean tubular length was $1.7 \pm 0.1 \mathrm{~mm}$. The perfusion rate was $8.80 \pm 0.14,9.42 \pm 0.21$, and $9.49 \pm 0.14$ in the control, experimental, and recovery periods, respectively. Fig. 6 shows the results. These data are consistent with insulin-stimulating neutral active $\mathrm{NaCl}$ transport in the PCT.

The final group of experiments examined whether the addition of $10^{-8} \mathrm{M}$ insulin to the lumen affected $J_{\mathrm{v}}$ and PD. The mean tubular length was $1.5 \pm 0.1 \mathrm{~mm}$ and the perfusion rate was $10.92 \pm 0.39$ and $10.51 \pm 0.29 \mathrm{nl} / \mathrm{min}$ in the control and experimental periods, respectively. Fig. 7 shows the results. Addition of insulin to the luminal perfusate had no affect on $J_{\mathrm{v}}$ or PD.
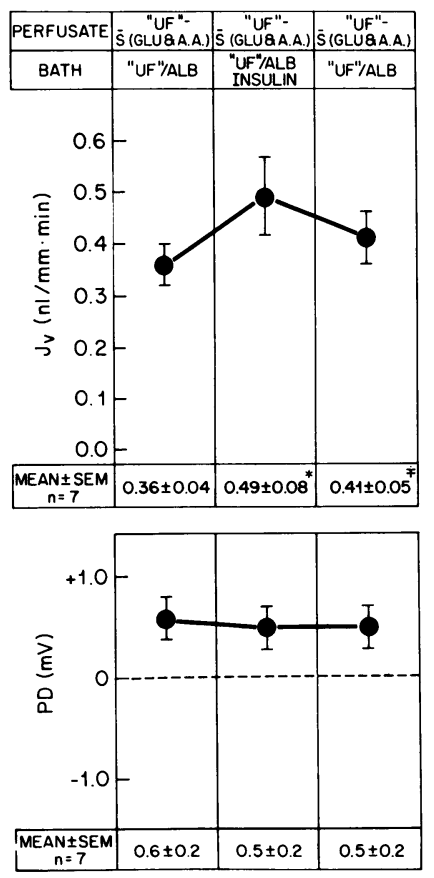

Figure 4. Effect of $10^{-8} \mathrm{M}$ bath insulin on $J_{v}$ and PD in PCT perfused without glucose and amino acids. ${ }^{*} P<0.05 ; \ddagger 0.05$ $<P<0.10$. 
Table II. Effect of $10^{-8} \mathrm{M}$ Bath Insulin

on $P D, J_{v}, J_{G l u}, J_{C l}$ and $J_{T C O_{2}}$

\begin{tabular}{lccc}
\hline & Control & Experimental & Recovery \\
\hline $\mathrm{PD}(\mathrm{mV})$ & $-4.4 \pm 0.4$ & $-5.7 \pm 0.5^{*}$ & $-5.7 \pm 0.5$ \\
$J_{\mathrm{v}}(\mathrm{nl} / \mathrm{mm} \cdot \mathrm{min})$ & $0.86 \pm 0.04$ & $1.07 \pm 0.06^{*}$ & $1.04 \pm 0.06$ \\
$J_{\mathrm{Glu}}(\mathrm{pmol} / \mathrm{mm} \cdot \mathrm{min})$ & $39.9 \pm 2.1$ & $46.9 \pm 3.4^{*}$ & $46.4 \pm 2.8$ \\
$J_{\mathrm{TCO}_{2}}(\mathrm{pmol} / \mathrm{mm} \cdot \mathrm{min})$ & $53.2 \pm 3.7$ & $65.9 \pm 4.1^{*}$ & $62.9 \pm 5.0$ \\
$J_{\mathrm{C}}(\mathrm{pmol} / \mathrm{mm} \cdot \mathrm{min})$ & $39.2 \pm 6.3^{\ddagger}$ & $68.6 \pm 11.6^{\ddagger}$ & $62.3 \pm 8.1$ \\
\hline
\end{tabular}

*Mean paired difference from control at the 0.01 level.

${ }^{\ddagger}$ Mean paired difference from control at the 0.05 level.

\section{Discussion}

The present in vitro microperfusion study examined whether insulin has a direct effect on the proximal tubule. Addition of a physiologic concentration of $10^{-10} \mathrm{M}$ insulin to the bathing solution resulted in a stimulation in $J_{v}$ in the PCT. Pharmacologic concentrations of insulin produced a greater stimulation of $J_{v}$ with a maximum response occurring at about $10^{-8} \mathrm{M}$ insulin. This stimulation in $J_{\mathrm{v}}$ was accompanied by an increase in the transepithelial PD. The stimulation of $J_{\mathrm{v}}$ by insulin was not dependent on luminal glucose and amino acids. Insulin stimulates glucose, chloride, and bicarbonate transport. Addition of insulin to the luminal perfusate had no effect on $J_{v}$ and PD. These data demonstrate that insulin stimulates $J_{v}$ in the proximal tubule.

The interaction of insulin with the renal proximal tubular cell has recently been extensively reviewed (19). Renal cortical membranes have high affinity receptors that bind insulin at physiologic concentrations (6-11). Insulin receptors are present on both the apical and basolateral membranes, but binding is much greater in basolateral membranes (8). Insulin binding not only affects solute transport as demonstrated in this study, but also is important for insulin degradation (7-9). Although binding is more avid on the basolateral membrane, insulin degradation occurs at a greater rate on the apical membrane (8).

Insulin binding is not homogeneous along the nephron. Specific binding is greatest in the medullary thick ascending limb, distal convoluted tubule and proximal tubule when expressed as a function of tubular length. However, insulin binding is greatest in the medullary and cortical thick ascending limb and

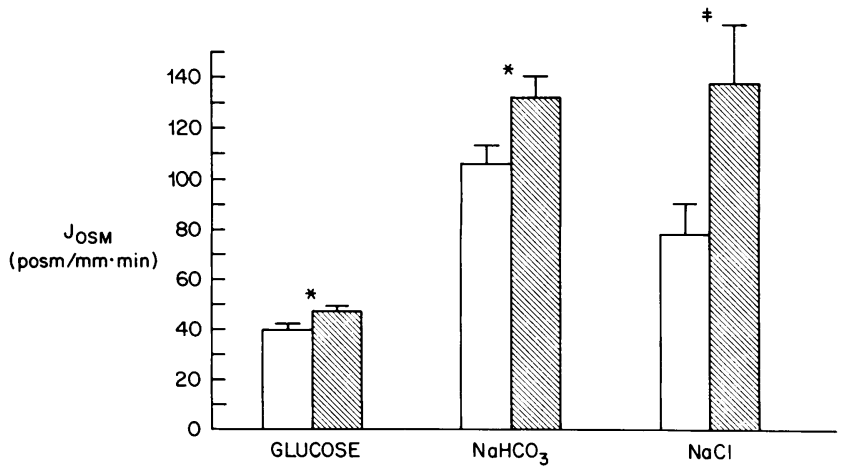

Figure 5. Effect of $10^{-8} \mathrm{M}$ bath insulin on glucose, bicarbonate, and chloride transport. *Mean paired difference from control at the 0.01 level. ¥Mean paired difference from control at the 0.05 level.
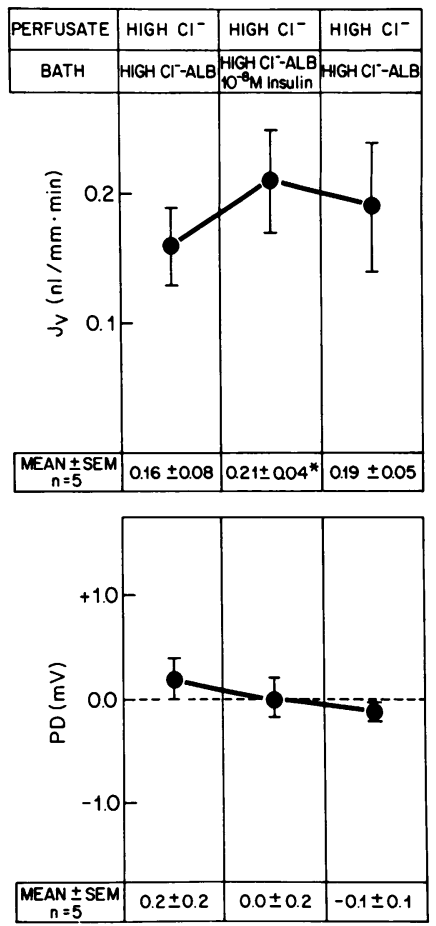

Figure 6. Effect of $10^{-8} \mathrm{M}$ bath insulin on active $\mathrm{NaCl}$ transport. *Mean paired difference from control at the 0.05 level.

distal convoluted tubule and similar in other segments when expressed per milligram of protein (9). Direct examination of the proximal tubule reveals high affinity, high specificity binding with significant binding at $10^{-10} \mathrm{M}$ insulin. $50 \%$ inhibition of ${ }^{125} \mathrm{I}$-labeled insulin binding occurred with $10^{-9} \mathrm{M}$ unlabeled insulin and did not increase with insulin concentrations $>10^{-8}$ M (11). These binding studies are in good agreement with the concentration of insulin resulting in a stimulation in $J_{\mathrm{v}}$. In the present study $10^{-11} \mathrm{M}$ insulin had no significant effect on $J_{\mathrm{v}}$.

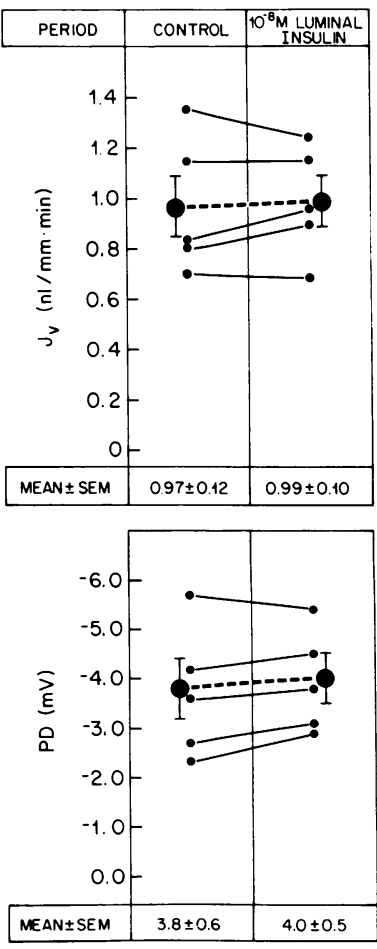

Figure 7. Effect of $10^{-8} \mathrm{M}$ luminal insulin on $J_{\mathrm{v}}$ and PD in the PCT. 
Addition of $10^{-10} \mathrm{M}$ insulin caused a $13 \%$ increase in $J_{\mathrm{v}} .10^{-9}$ $M$ insulin increased $J_{v}$ by $20 \%$. Higher concentrations resulted in a $30-35 \%$ increase in $J_{v}$, which remained after removal of insulin from the bathing solution. Insulin also resulted in a dosedependent stimulation in the transepithelial PD. This increase in the lumen negative PD remained after bath insulin was removed at concentrations $>10^{-10} \mathrm{M}$. The reason for the continued stimulation in $J_{v}$ with higher concentrations of insulin and the persistent stimulation in the transepithelial PD observed is unclear. It is possible that insulin has a long term tonic effect, which allows for the acute expression of another factor in vivo. For example, physiologic concentrations of insulin increase the binding of insulin-like growth factors to adipocytes $(20,21)$. Insulin may play a permissive role to allow the expression of another hormone in vivo. However, this study clearly demonstrates that insulin has a direct effect to stimulate transport in the PCT in vitro.

Previous studies have demonstrated that insulin increases whole kidney sodium reabsorption $(2,4,5)$. The mechanism whereby insulin stimulates sodium transport and the nephron segments involved is unclear. Earlier studies have provided evidence against insulin-stimulated $J_{\mathrm{v}}$ in the proximal tubule and have suggested that insulin stimulates sodium transport in the distal nephron $(4,5)$. Insulin stimulated free water excretion in clearance studies performed on water loaded normal human subjects who were in a state of water diuresis (4). The study suggests that insulin increases solute transport in the thick ascending limb. Micropuncture studies have also suggested that insulin increases sodium transport in the distal nephron. In euglycemic hyperinsulinemic dogs whose glomerular filtration rate and renal blood flow remained constant, there was a decrease in the fractional excretion of sodium. Proximal tubule $J_{\mathrm{v}}$ was inhibited under these conditions, suggesting that the stimulation of sodium transport was by the distal nephron (5). In volumeexpanded parathyroidectomized rats, somatostatin infusion resulted in a decrease in plasma insulin concentration and an increase in the fractional excretion of sodium. Under these conditions there was no change in $J_{\mathrm{v}}$ by the proximal tubule and no detectable change in $J_{v}$ by the early and late distal tubule. These studies provide evidence against a stimulation of $J_{v}$ by the proximal tubule. The reason for the difference in the results between these studies and the current study is unclear. Although the above studies found no change in glomerular filtration rate, recent data suggests that insulin may increase glomerular filtration rate. Addition of physiologic concentrations of insulin to isolated perfused kidneys from male Sprague Dawley rats resulted in an increase in glomerular filtration rate (22). Small changes in glomerular filtration rate can have substantial effects on the filtered load delivered to the proximal tubule and obscure an increase in $J_{\mathrm{v}}$. It is also possible that under the conditions used to alter insulin concentration in vivo other hormones may have also been affected which could have suppressed $J_{\mathrm{v}}$ by the proximal tubule. The current study was able to directly examine whether insulin affects $J_{v}$ independent of filtered load or other hormones. The data show that insulin has a direct epithelial effect to stimulate $J_{\mathrm{v}}$ in the proximal tubule.

The mechanism for the observed stimulation in $J_{\mathrm{v}}$ is unknown. The fact that insulin caused an increase in the lumen negative transepithelial PD in tubules perfused with an ultrafiltrate-like solution suggests that insulin stimulates amino acid and glucose transport. To examine whether insulin affected the transport of other solutes, glucose and amino acids were removed from the luminal perfusion solution. Insulin resulted in an increase in $J_{v}$ under these conditions consistent with insulin stimulating the transport of other solutes besides glucose and amino acids. To examine this directly, the effect of insulin on glucose, chloride, and bicarbonate absorption was examined. Insulin stimulated the transport of each of these solutes. The stimulation of chloride transport may be greater than that of bicarbonate and glucose. The more negative PD and the larger anion gradient resulting from the insulin-induced stimulation of organic solute and bicarbonate transport will increase passive chloride transport (16). Active chloride transport may also be stimulated. To examine this, tubules were perfused with a high chloride solution simulating late proximal tubular fluid and bathed in a similar solution containing albumin. Under these conditions $\mathrm{NaCl}$ transport is entirely active $(14,16)$. Insulin stimulated $J_{\mathrm{v}}$ under these conditions consistent with insulin-stimulating neutral active $\mathrm{NaCl}$ transport as well as bicarbonate and glucose transport.

Previous studies have demonstrated that insulin stimulates renal phosphate reabsorption $(4,5,11,12,23)$. Infusion of insulin in humans where the plasma glucose concentration was maintained at a constant level resulted in a decrease in phosphate excretion (4). In parathyroidectomized rats insulin abolished the phosphaturia induced by parathyroid hormone infusion (23). Micropuncture studies have provided evidence that phosphate transport in the proximal tubule is enhanced by insulin. Proximal tubule phosphate transport was stimulated in hyperinsulinemic euglycemic rats (5). Hypoinsulinemia induced by somatostatin infusion in parathyroidectomized rats results in a decrease in proximal tubule phosphate transport (12). Brush border membrane vesicles prepared from dog isolated proximal tubules had an increase in sodium-dependent phosphate transport when insulin was added to the incubation media (11). This effect was enhanced by increasing the concentration of insulin. A significant stimulation occurred at $10^{-10} \mathrm{M}$ insulin and a maximal stimulation occurred at concentrations $>10^{-8} \mathrm{M}$.

Insulin has been shown to stimulate transport in other epithelia (22-27). Insulin increases short-circuit current and sodium transport in amphibian skin and toad bladder (24-27). Exposure of renal proximal tubular cells grown in culture to insulin results in an increase in $\mathrm{Na}^{+} / \mathrm{H}^{+}$antiporter activity (28). In many tissues insulin stimulates $\mathrm{Na}^{+} / \mathrm{K}^{+}$-ATPase (29).

The present study demonstrates that insulin has a direct dosedependent effect to stimulate transport in the PCT when added to the bath but not the lumen. The insulin-induced stimulation in transport is present at physiologic concentrations. Insulin stimulates glucose as well as bicarbonate and chloride absorption in the PCT.

\section{Acknowledgments}

I thank Juha P. Kokko and Diana Marver for their continued support. I am grateful for the technical assistance of Rebecca Aricheta and the able secretarial assistance of Janell McQuinn.

This work was supported by National Institutes of Health grants AM-14677-16 and AM-38465-01.

\section{References}

1. Atchley, D. W., R. F. Loeb, D. W. Richards, Jr., E. M. Benedict, and M. E. Driscoll. 1933. On diabetic acidosis. J. Clin. Invest. 12:297326.

2. Nizet, A., P. LeFrebre, and R. Crabbe. 1971. Control by insulin 
of sodium potassium and water excretion by the isolated dog kidney. Pfleugers Arch. Eur. J. Physiol. 323:11-20.

3. Saudek, C. D., P. R. Boulter, R. H. Knopp, and R. A. Arky. 1974. Sodium retention accompanying insulin treatment of diabetes mellitus. Diabetes. 23:240-246.

4. DeFronzo, R. A., C. R. Cooke, R. Andres, G. R. Fabona, and P. J. Davis. 1975. The effect of insulin on renal handling of sodium, potassium, calcium, and phosphate in man. J. Clin. Invest. 55:845-855.

5. DeFronzo, R. A., M. Goldberg, and Z. S. Agus. 1976. The effects of glucose and insulin on renal electrolyte transport. J. Clin. Invest. 58: 83-90.

6. Blanchard, R. F., P. J. David, and S. D. Blas. 1978. Physical characteristics of insulin receptors on renal cell membranes. Diabetes. 27: 88-95.

7. Kurokawa, K., and R. L. Lerner. 1980. Binding and degradation of insulin by isolated renal cortical tubules. Endocrinology. 106:655662.

8. Talor, Z., D. S. Emmanouel, and A. I. Katz. 1982. Insulin binding and degradation by luminal and basolateral tubular membranes from rabbit kidney. J. Clin. Invest. 69:1136-1146.

9. Nakamura, R., D. S. Emmanouel, and A. I. Katz. 1983. Insulin binding sites in various segments of the rabbit nephron. J. Clin. Invest. 72:388-392.

10. Hammerman, M. R., and J. R. Gavin, III. 1984. Insulin-stimulated phosphorylation and insulin binding in canine renal basolateral membranes. Am. J. Physiol. 247:F408-F417.

11. Hammerman, M. R., S. Rogers, V. A. Hansen, and J. R. Gavin, III. 1984. Insulin stimulates Pi transport in brush border vesicles from proximal tubular segments. Am. J. Physiol. 247:E616-E624.

12. Lau, K., J. Guntupalli, and B. Eby. 1983. Effects of somatostatin on phosphate transport: evidence for the role of basal insulin. Kidney Int. 24:10-15.

13. Burg, M. B., J. Grantham, M. Abramow, and J. Orloff. 1966. Preparation and study of fragments of single rabbit nephrons. Am. J. Physiol. 210:1293-1298.

14. Baum, M., and C. A. Berry. 1985. Peritubular protein modulates neutral active $\mathrm{NaCl}$ transport in the rabbit proximal convoluted tubule. Am. J. Physiol. 248:F790-F795.

15. Baum, M., and R. D. Toto, 1986. Lack of a direct effect of atrial natriuretic factor in the rabbit proximal tubule. Am. J. Physiol. 250: F66-F69.
16. Baum, M., and C. A. Berry. 1984. Evidence for neutral transcellular $\mathrm{NaCl}$ transport and neutral basolateral chloride exit in the rabbit proximal convoluted tubule. J. Clin. Invest. 74:205-211.

17. Vurek, G. G., D. G. Warnock, and R. Corsey. 1975. Measurement of picomole amounts of carbon dioxide by calorimetry. Anal. Chem. 47: 765-767.

18. Ramsay, J. A., R. H. Brown, and P. C. Croghan. 1955. Electrometric titration of chloride in small volumes. J. Exp. Biol. 34:822-829.

19. Hammerman, M. R. 1985. Interaction of insulin with the renal proximal tubular cell. Am. J. Physiol. 249:F1-F11.

20. King, G. L., M. M. Rechler, and C. R. Kahn. 1982. Interactions between the receptors for insulin and the insulin-like growth factors on adipocytes. J. Biol. Chem. 257:10001-10006.

21. Oppenheimer, C. L., J. E. Pessin, J. Massague, W. Gitomer, and M. P. Czech. 1983. Insulin action rapidly modulates the apparent affinity of the insulin-like growth factor II receptor. J. Biol. Chem. 258:48244830.

22. Cohen, A., and D. McCarthy. 1986. Effect of insulin on the isolated perfused kidney. Kidney Int. 29:382A. (Abstr.).

23. Guntupalli, J., A. Rogers, and E. Bourke. 1985. Effect of insulin on renal phosphorus handling in the rat: interaction with PTH and nicotinamide. Am. J. Physiol. 249:F610-F618.

24. Herrera, F. C., G. Whittembury, and A. Planchart. 1963. Effect of insulin on short-circuit current across isolated frog skin the presence of calcium and magnesium. Biochim. Biophys. Acta. 66:170-172.

25. Herrera, F. C. 1965. Effect of insulin on short-circuit current and sodium transport across toad urinary bladder. Am. J. Physiol. 209:819824.

26. Andre, R., and J. Crabbé. 1966. Stimulation by insulin of active sodium transport by toadskin: influence of aldosterone and vasopressin. Arch. Int. Physiol. Biochim. 74:538-540.

27. Francois, B., M. de Gasparo, and J. Crabbe. 1969. Interaction between isolated amphibian skin and insulin. Arch. Int. Physiol. Biochim. 77:527-530.

28. Fine, L. G., B. Badie-Dezfooly, A. G. Lowe, A. Hamzeh, J. Wells, and S. Salehmoghaddam. 1985. Stimulation of $\mathrm{Na}^{+}-\mathrm{H}^{+}$antiport is an early event in hypertrophy of renal proximal tubular cells. Proc. Natl. Acad. Sci. USA. 82:1736-1740.

29. Moore, R. D. 1983. Effect of insulin upon ion transport. Biochim. Biophys. Acta. 737:1-49. 